\title{
THYROID AUTOIMMUNITY HAS NO NEGATIVE IMPACT ON INSULIN DYNAMICS IN PREDIABETIC PATIENTS WITH NORMAL THYROID FUNCTION
}

\author{
Krystallenia I. ALEXANDRAKI ${ }^{1 凶}$, Georgios BOUTZIOS ${ }^{2}$, loanna ANTONOPOULOU ${ }^{1}$, \\ Theodoros G. PAPAIOANNOU ${ }^{3}$, Lamprini Iro BARTSIOKA ${ }^{1}$, Panagiotis MOSCHOURIS ${ }^{1}$, \\ Angeliki KARAPANAGIOTI ${ }^{1}$, Vasiliki MAVROEIDI ${ }^{1}$, Konstantinos MAKRILAKIS ${ }^{4}$, \\ Leonidas DUNTAS ${ }^{5}$, Gregory A. KALTSAS ${ }^{1}$, Stavros LIATIS ${ }^{4}$
}

${ }^{1}$ Endocrine Unit, First Department of Propaedeutic Internal Medicine, Medical School, Laiko Hospital, National and Kapodistrian University of Athens, Athens, Greece

${ }^{2}$ Endocrine Unit, Department of Pathophysiology, Laiko Hospital, Medical School, National and Kapodistrian University of Athens, Athens, Greece

${ }^{3}$ First Department of Cardiology, Medical School, National and Kapodistrian University of Athens, Athens, Greece

${ }^{4}$ Diabetes Center, First Department of Propaedeutic Internal Medicine, Laiko Hospital, Medical School, National and Kapodistrian University of Athens, Athens, Greece

${ }^{5}$ Endocrine Unit, Evgenidion Hospital, National and Kapodistrian University of Athens, Athens, Greece

Received 13 March 2020, Accepted 03 May 2020

https://doi.org/10.31688/ABMU.2020.55.2.02

\section{Abstract}

Introduction. The association of autoimmune thyroid disease (AITD) with diabetes mellitus type-1 (DM1) has been previously documented. However, limited data exist regarding the association of AITD and diabetes mellitus type-2 (DM2).

The objective of the study was to expose the role of AITD on DM2 and the impact of AITD in euthyroid patients with pre-diabetes. Euthyroid prediabetic patients were defined by impaired fasting glucose and/or glucose intolerance. We assessed static and dynamic insulin resistance (IRI) and insulin secretion indices (ISI), and the disposition index (DI).

\section{Résumé}

Lauto-immunité thyroïdienne n'a pas d'impact négatif sur la dynamique de l'insuline chez les patients prédiabétiques ayant une fonction thyroïdienne normale

Introduction. L'association de la maladie thyroïdienne auto-immune (MAIT) avec le diabète de type 1 (DT1) a déjà été documentée. Cependant, des données limitées existent concernant l'association du MAIT et du diabète de type 2 (DT2).

Le but de l'étude était de présenter le rôle de MAIT sur le DT2 et d'explorer l'impact du MAIT chez les 
Results. Out of 166 patients studied, 31.9\% had AITD; impaired fasting glucose (IFG) prevalence was the same with non-AITD patients. In contrast, impaired glucose tolerance (IGT) was less prevalent in AITD compared to non-AITD patients $(9.4 \%$ versus $28.3 \%, p=0.008$ ). IRI did not differ between the two groups. The dynamic ISI, $1^{\text {st }}$ phase and $2^{\text {nd }}$ phase insulin release, and the DI showed a worse insulin secretion in non-AITD compared to AITD patients $(0.54$ versus $0.45, p=0.029 ; 1029.3$ versus $864.3, p=0.033$; 354.8 versus $286.5, p=0.035 ; 0.09$ versus $0.07, p=0.02$, respectively). On the other hand, hsCRP was higher in AITD versus non-AITD individuals $(\mathrm{p}=0.008)$.

Conclusions. Although individuals with pre-diabetes and AITD presented with higher levels of low-grade inflammation, their dynamic ISI and the DI, were less impaired.

Keywords: insulin resistance indices, QUICKI, HOMA, disposition index, glucose-to-insulin ratio.

\section{List of abbreviations:}

AITD: autoimmune thyroid disease

Anti-GAD: Antibodies to glutamic acid decarboxylase

BMI: body mass index

DBP: diastolic blood pressure

DI: disposition index

DM: diabetes mellitus

DM1: diabetes mellitus type 1

DM2: diabetes mellitus type 2

GIR: glucose-to-insulin ratio

HbAlc: glycosylated hemoglobulin

HOMA: Homeostasis model assessment

HOMA-B: HOMA index of $\beta$-cell function

HOMA-IR: insulin resistance HOMA

hs-CRP: high-sensitive C-reactive protein

IFG: impaired fasting glucose

IGT: impaired glucose tolerance

IL: interleukin

incAUCins/glu: incremental area under the insulin to

glucose curve

IQR: interquartile range

ISI: insulin secretion index

IRI: insulin resistance index

NHANES III: National Health and Nutrition

Examination Survey

OGTT: oral glucose tolerance test

QUICKI: quantitative insulin sensitivity check index

SBP: systolic blood pressure

SD: standard deviation

SISI: Static ISI

TNF- $\alpha$ : tumor necrosis factor- $\alpha$

TPOAb: thyroid peroxidase antibodies

TSH: thyroid stimulating hormone

WHR: waist-to-height ratio

$1^{\text {st }}$ PHIS: predicted index of first phase of insulin secretion $2^{\text {nd }}$ PHIS: predicted index of second phase of insulin secretion patients euthyroïdiens prédiabétiques. Les patients prédiabétiques euthyroïdiens étaient définis par une altération de la glycémie à jeun et / ou une intolérance au glucose.

Matériel et méthodes. Nous avons évalué la résistance à l'insuline statique et dynamique (IRI), les indices de sécrétion d'insuline (ISI) et l'indice de disposition (DI).

Résultats. Sur 166 patients étudiés, 31.9\% avaient une MAIT; La prévalence du glucose à jeun altéré (IFG) était similaire à celle des patients non MAIT. En revanche, l'IGT était moins répandue dans les MAIT par rapport aux patients non-MAIT $(9.4 \%$ contre $28.3 \%, \mathrm{p}=0.008$ ). L'IRI ne diffère pas entre les deux groupes. L'ISI dynamique, la libération d'insuline des lères et 2èmes phases, et la DI ont montré une sécrétion d'insuline pire dans les non-MAIT par rapport aux patients MAIT $[0.54$ contre $0.45, \mathrm{p}=0.029 ; 1029.3$ contre 864.3, $\mathrm{p}=0.033 ; 354.8$ contre 286.5, $\mathrm{p}=0.035$; 0.09 contre $0.07, p=0.02$, respectivement. En revanche, le hsCRP était plus élevé chez les individus MAIT que chez les non-MAIT ( $p=0.008)$.

Conclusions. Bien que les personnes prédiabétiques et avec AITD présentent des niveaux plus élevés d'inflammation à bas degré, ISI dynamique et $\mathrm{D}$ étaient moins altérés.

Mots-clés: indices de résistance à l'insuline, QUICKI, HOMA, indice de disposition, rapport glucose / insuline. 


\section{INTRODUCTION}

Autoimmune thyroid disease (AITD) and disorders of carbohydrate metabolism are common endocrine disorders in the general population ${ }^{1,2}$. In a large Nordic unselected population-based study, the prevalence of positive thyroid peroxidase antibodies (TPOAb) was $13.9 \%$ in females and $2.8 \%$ in males ${ }^{2}$. Similarly, in another large series of National Health and Nutrition Examination Survey (NHANES III) in the United States population, anti-thyroglobulin antibodies $(\mathrm{TgAb})$ were positive in $10.4 \pm 0.5 \%$ and $\mathrm{TPOAb}$, in $11.3 \pm 0.4 \%$; positive antibodies increased with age with a clear female preponderance ${ }^{3}$. On the other hand, a national study from a European country, Spain, revealed that $30 \%$ of the population had abnormal carbohydrate metabolism. In particular, the adjusted for age and sex prevalence of established diabetes mellitus type 2 (DM2) was $13.8 \%$ (95\%CI: 12.8, $14.7 \%$ ), whereas the prevalence of pre-diabetic states was 3.4\% (95\%CI: $2.9,4.0 \%)$ for isolated impaired fasting glucose (IFG), 9.2\% (95\%CI: 8.2, 10.2\%) for isolated impaired glucose tolerance (IGT) and 2.2\% (95\%CI: 1.7, 2.7\%) for combined IFG-IGT ${ }^{4}$. Both DM2 and IGT increased significantly with age, being also more prevalent in men than in women ${ }^{4}$. Moreover, oral glucose tolerance test (OGTT)-based studies in Europe documented a prevalence of pre-diabetes (including IFG, IGT) ranging from $14 \%$ in Spain to 30\% in Turkey ${ }^{1}$.

The association between AITD and alterations in glucose homeostasis has been reported since $1979^{5,6}$. In 1310 adult persons with DM, 13.4\% had thyroid dysfunction (clinical and subclinical hypothyroidism or hyperthyroidism) with the highest prevalence in diabetes type 1 (DM1) (31.4\%) and the lowest in DM2 (6.9\%) tion among Greek diabetic patients, as defined by the need for thyroxin administration, use of antithyroid drugs, history of thyroidectomy, radioactive iodine treatment, was $12.3 \%$, with women being more frequently affected than men ${ }^{8}$. In another study, in diabetic patients, the prevalence of thyroid dysfunction defined by the presence of either hypothyroidism or hyperthyroidism (clinical and/or subclinical) was found to be $14.7 \%$, whereas TPOAb were positive in $10.8 \%$. Inversely, DM2 was present in $27.8 \%$ of patients with AITD, whereas IFG or IGT occurred in $16.6 \%{ }^{10}$. Despite the apparent association of DM with thyroid dysfunction, specific studies addressing potential associations of AITD have been performed mainly in DM1 $1^{11-13}$, whereas there is limited and occasionally contradictory information in DM2 patients ${ }^{14}$.

Recently, in a large series of 9082 euthyroid subjects, AITD was positively related to HbA1c, IRI, obesity, central obesity, hyperlipidemia, and metabolic syndrome, especially in women ${ }^{15}$. This specific study highlighted that AITD per se may be a potential risk factor for the development of cardiometabolic disorders since the investigators abrogated the negative effect of abnormal thyroid stimulating hormone (TSH) (hypothyroidism or hyperthyroidism) on glucose metabolism ${ }^{15-16}$.

These are relatively common diseases and some patients with apparent DM2 may have an underlying autoimmune component.

The obJective OF THE STUdY was to investigate the possible impact of AITD on insulin secretion and insulin resistance indices (ISI, IRI, respectively), in a population of individuals with prediabetes.

\section{Materials AND Methods}

Subjects

The study included subjects recruited from the Diabetic and Endocrine Outpatient Clinic of the Laiko University Hospital in Athens, Greece. The study was approved by the Scientific Committee of „Laiko" University Hospital (47/14.01.2013). We recruited patients with pre-diabetes, defined by the presence of one of the following criteria: i) IGT defined by serum glucose level at 120 minutes $\geq 140 \mathrm{mg} /$ dL $(7.77 \mathrm{mmol} / \mathrm{L})$ but $<200 \mathrm{mg} / \mathrm{dL}(11.1 \mathrm{mmol} / \mathrm{L})$, following a formal $75 \mathrm{~g}$ OGTT, ii) IFG defined by fasting serum glucose levels $\geq 100 \mathrm{mg} / \mathrm{dL}(5.55 \mathrm{mmol} / \mathrm{L})$ but $<126 \mathrm{mg} / \mathrm{dL}(6.99 \mathrm{mmol} / \mathrm{L})$, according to ADA criteria $^{17}$. Autoimmune thyroid disease was defined by the presence of $\operatorname{Tg} A b$ and/or TPOAb antibodies. The population was divided into two groups, patients with AITD and patients without AITD.

All subjects under any medication known to affect glucose metabolism, those with abnormal thyroid function [TSH $\geq 5 \mu \mathrm{IU} / \mathrm{mL}$ (mIU/L)] defined as subclinical/ clinical hypothyroidism or TSH $<0.5 \mu \mathrm{IU} /$ $\mathrm{mL}$ (mIU/L) as subclinical/ clinical hyperthyroidism) and individuals with thyroidectomy were excluded. Pregnant women and individuals with a history of hospitalization during the last 6 months, and hemoglobin levels less than $12 \mathrm{~g} / \mathrm{dL}$ were also excluded from the study.

Oral glucose tolerance test was performed after 10 hrs overnight fast. Serum glucose (mg/dL) and insulin levels $(\mu \mathrm{IU} / \mathrm{mL})$, were measured at baseline and at 30 min intervals (30', 60', 90', 120'). Glycosylated hemoglobulin (HbAlc, \%) and high-sensitive C-reactive protein (hs-CRP) were also measured. Plasma glucose, total cholesterol, high density kipoprotein (HDL)-cholesterol, low density lipoprotein (LDL)-cholesterol and triglycerides were measured, 
as previously described ${ }^{18}$. Percent concentration of $\mathrm{HbAlc}$ was performed in vitro in whole blood with an immunological method (tholosimetric suppression immuno-analysis, TINI $\alpha$ ) in an automatic analyzer of clinical chemistry (Hitachi 912, Roche, France). Serum insulin was measured with the immunoradiometric assay IRMA (DIA source Immuno-Assays, Louvain-la-Neuve, Belgium). High sensitivity-CRP $(\mathrm{mg} / \mathrm{L})$ serum levels were determined by enzyme immunoassay test kit (LI7500, Linear Chemicals, S.L., 08390 Montgat, Barcelona, Spain). The intra- and inter-assay coefficients of variance for hsCRP were 7.5 and $4.1 \%$ for low levels and 2.3 and $2.5 \%$ for high levels, respectively.

Arterial hypertension was diagnosed according to each individual's medical and drug history or in the presence of systolic blood pressure (SBP) $\geq 135 \mathrm{mmHg}$ and/or diastolic blood pressure (DBP) $\geq 85 \mathrm{mmHg}$ ) [mean value of latest European guidelines (SBP/DBP >140/90 mm Hg) and the American guidelines (SBP/DBP <130/80 mm Hg) ${ }^{18-21}$. Dyslipidemia was diagnosed based on the LDL levels $\geq 130 \mathrm{mg} / \mathrm{dL}$ $(3.36 \mathrm{mmol} / \mathrm{L})$ and the administration of hypolipidemic drugs ${ }^{22}$.

Body weight was measured using analogue scales in light clothing; height was measured bare foot using a stadiometer. Body mass index (BMI, kg/ $\mathrm{m}^{2}$ ) was calculated to assess obesity and waist and waist-to-height ratio (WHR) to assess body fat distribution. Antibodies to glutamic acid decarboxylase (anti-GAD) were randomly measured in the first 25 persons that were enrolled into the study to test for the case of persons with Latent Autoimmune Diabetes of Adults.

\section{Indices of carbohydrate metabolism - insulin resistance indices (IRI)}

\section{Static IRI}

$1 /$ fasting insulin, fasting glucose-to-insulin ratio (GIR), the quantitative insulin sensitivity check index (QUICKI), and insulin resistance Homeostasis model assessment (HOMA) (HOMA-IR) were used to assess insulin action ${ }^{23}$ in the fasting state, using the following formulas:

$$
\begin{aligned}
& \begin{array}{l}
\text { QUICKI }=1 /(\log (\text { fasting insulin } \mu \mathrm{U} / \mathrm{mL})+ \\
\quad+\log (\text { fasting glucose } \mathrm{mg} / \mathrm{dL})^{24}
\end{array} \\
& \text { HOMA-IR }=\text { fasting insulin }(\mu \mathrm{IU} / \mathrm{mL}) \times \\
& \times \text { fasting glucose }(\mathrm{mmol} / \mathrm{mL}) / 22.5^{52} .
\end{aligned}
$$

\section{Dynamic IRI}

The Matsuda index was used to assess dynamic insulin action using the following formula:
Matsuda index $=(10,000 /$ square root of [fasting glucose $\times$ $\times$ fasting insulin] $\times$ [mean glucose $x$ mean insulin during OGTT] $)^{26}$

$\beta$-cell secretion indices (ISI)

Static ISI (SISI)

HOMA index of $\beta$-cell function (HOMA-B) was calculated using the following formula:

$$
\begin{gathered}
\text { HOMA-B }=20 \times \text { fasting insulin }(\mu \mathrm{IU} / \mathrm{mL}) / \\
/[\text { fasting glucose }(\mathrm{mmol} / \mathrm{mL})-3.5]^{27} .
\end{gathered}
$$

\section{Dynamic ISI}

First phase and second phase insulin secretion and the incremental area under the insulin to glucose curve (incAUCins/glu) were used, by the following formulas ${ }^{28}$ :

Predicted index of first phase of insulin secretion $(1$ st PHIS $)=1283+[1.289 x$ insulin at 30 minutes $(\mathrm{pmol} / \mathrm{L})]-[138.7 \times$ glucose at 30 minutes $(\mathrm{mmol} / \mathrm{L})]$ $+[3.772 x \text { insulin at baseline }(\mathrm{pmol} / \mathrm{L})]^{29}$

Predicted index of second phase of insulin secretion $(2 n d$ PHIS $)=287+[0.4164 x$ insulin at 30 minutes $(\mathrm{pmol} / \mathrm{L})]-[26.07 \times$ glucose at 30 minutes $(\mathrm{mmol} / \mathrm{L})]+$

$+[0.9226 x \text { insulin at baseline }(\mathrm{pmol} / \mathrm{L})]^{29}$

IncAUCins/glu by the trapezoidal method from $0^{\prime}$ to $120^{\prime} \min ^{23}$

\section{Combined index}

The combined index of insulin action and $\beta$-cell secretion is expressed by the disposition index (DI) and the following formula is used:

$$
\begin{gathered}
\text { Oral disposition index }(\mathrm{DI})=\Delta \mathrm{IO}-30 / \Delta \mathrm{G} 0-30 \times 1 / \\
/ \text { fasting insulin }{ }^{27} .
\end{gathered}
$$

The presence of insulin resistance was defined as previously described ${ }^{28}$ : HOMA-IR > 2.16 and/or QUICKI $<0.34$ values.

\section{Assays}

The serum TSH levels were measured by a sensitive two-site chemiluminescent immunometric assay with analytical sensitivity: $0.004 \mu \mathrm{IU} / \mathrm{mL}$, and the coefficient of variation (CV) is less than $5.5 \%$ for TSH values comprising between 0.3 and $10 \mu \mathrm{UI} / \mathrm{mL}$. Thyroid antibodies: $\mathrm{TgAb}<40 \mathrm{U} / \mathrm{mL}$ with analytical sensitivity $20 \mathrm{U} / \mathrm{mL}$ with an intra- and inter-assay $\mathrm{CV}$ of $3.2 \%$ and $4.6 \%$, respectively, and TPOAb < $30 \mathrm{U} / \mathrm{mL}$ with analytical sensitivity $10 \mathrm{U} / \mathrm{mL}$ with an intra- and inter-assay CV of $5.2 \%$ and $3.2 \%$, respectively (IMMULITE 2000 SIEMENS Healthcare Diagnostics Products Ltd. Llanberis, Gwynedd LL55 4EL United Kingdom). High-sensitive CRP (reference 
range $<5 \mathrm{mg} / \mathrm{L}$ ) was determined with a highly sensitive latex-based immunoassay. Anti-GAD antibodies were measured by ELISA (Anachem Ltd, Luton, UK).

\section{Statistical analysis}

A between-group comparison of categorical variables was carried out by Chi-square test corrected by Fisher's exact test when appropriate, while for the continuous variables a Student t-test for parametric and Mann-Whitney U test for non-parametric variables was used. Parametric variables are presented as mean value \pm one standard deviation (SD), and non-parametric variables as median values, interquartile range (IQR), minimum-to-maximum values range). A p value $<0.05$ was considered as statistically significant. SPSS software (SPSS 16. Inc. Chicago, IL) was used for the statistical analysis.

This section may be divided by subheadings. It should provide a concise and precise description of the experimental results, their interpretation as well as the experimental conclusions that can be drawn.

\section{Results}

One hundred sixty-six patients with pre-diabetes were recruited; 132 (79.5\%) were females. The median age was 50 years and median BMI $32.1 \mathrm{~kg} / \mathrm{m}^{2}$. Demographic and biochemical characteristics stratified by the presence or absence of AITD are shown in Table 1. The two groups did not differ in terms of age, gender, BMI, waist and waist-to-height ratio (Table 1).

Fifty-three patients (31.9\%) had AITD, 34 (64.2\%) of those with positive antibodies had positive TgAbs, 50 (94.3\%) had positive TPOAbs and $55.8 \%$ had both antibodies involved. Seventy (42.2\%) patients were on thyroxine replacement treatment. All the participants obtained normal thyroid function tests and the serum TSH levels did not differ between the two groups. As expected, more patients with AITD were on thyroxine replacement therapy, compared to non-AITD ( $p<0.001)$. One patient $(4 \%)$ out of 25 had positive anti-GAD antibodies. High sensitivity CRP levels were higher in AITD compared to non-AITD patients, $2.8(5,0-16) \mathrm{mg} / \mathrm{L}$ versus 1.2 $(3,0-13) \mathrm{mg} / \mathrm{L}[26.7(47.6,0-152.4) \mathrm{nmol} / \mathrm{L}$ versus $11.4(28.6,0-123.8) \mathrm{nmol} / \mathrm{L}], \mathrm{p}=0.008]$.

One hundred twenty-nine (92.2\%) patients had IFG and 37 (22.3\%) had IGT (Table 1). Seventy-seven (46.4\%) patients had isolated IFG, $13(7.8 \%)$ had isolated IGT with the remaining $54.2 \%$ presenting both abnormalities. IFG prevalence was similar in both groups (AITD: $94.3 \%$ versus $91.2 \%$, in non-AITD $\mathrm{p}=0.55$ ), as opposed to IGT which was less prevalent in $\operatorname{AITD~(9.4\% ~versus~} 28.3 \%$ in non-AITD, $\mathrm{p}=0.008)$.
Fasting serum glucose was similar between AITD and non-AITD individuals [AITD 104 (9, 86-124) mg/ dL $[5.77(0.5,4.77-6.88)] \mathrm{mmol} / \mathrm{L}$; non-AITD 104 $(10,74-125) \mathrm{mg} / \mathrm{dL}[5.77(0.56,4.11-8.55)] \mathrm{mmol} / \mathrm{L}$, $\mathrm{p}=0.36$. However, $1 \mathrm{hr}$ and $2 \mathrm{hrs}$ post load serum glucose was higher in the non-AITD group, both reaching statistical significance [glucose $60 \mathrm{~min}$ : AITD 157 (54, 65-227) mg/dL [8.71 (3, 3.61-13.15) $\mathrm{mmol} / \mathrm{L}]$; non-AITD 169 (63, 78-275) mg/dL [9.38 $(3.5,4.33-15.26) \mathrm{mmol} / \mathrm{L}], \mathrm{p}=0.06$; glucose $120 \mathrm{~min}$ : AITD 100 (40, 56-199) mg/dL [5.55 (2.22, 3.11-11.04) $\mathrm{mmol} / \mathrm{L}]$; non-AITD 112 (59, 40-199) mg/dL [6.22 $(3.27,2.22-199) \mathrm{mmol} / \mathrm{L}] \mathrm{p}=0.07]$. One hundred twenty-one $(72.9 \%)$ patients had IR, either by HOMA-IR and/or QUICKI criteria (Table 1).

Static IRI, dynamic IRI and static ISI did not differ between patients with and without AITD. In contrast, dynamic ISI indices, namely IncAUCins/ glu, $1^{\text {st }}$ phase and $2^{\text {nd }}$ phase insulin release, as well as DI, were significantly higher in non-AITD compared to AITD patients (refer to table). DISI indices in AITD individuals were higher irrespective of gender, BMI and HbAlc.

\section{Discussion}

The present study provides data suggesting that individuals with pre-diabetes and AITD display a better $\beta$-cell insulin secretory profile compared to patients without AITD, for the same level of insulin resistance and despite having a higher level of low-grade chronic inflammation. This finding may simply suggest that thyroid autoimmunity does not confer any additional $\beta$-cell secretory dysfunction or, that prediabetics with AITD, in order to overcome a similar insulin resistance state as a population without AITD, have to increase their overall $\beta$-cell secretion. Since, however, as DI which is a more accurate marker of $\beta$-secretory capacity (as it takes into account the level of insulin resistance) was significantly higher in the AITD group, it seems reasonable to assume that $\beta$-cell "health" in the AITD group is better than in the non-AITD group. Indeed, this is reflected in the plasma glucose values at $1 \mathrm{hr}$ and $2 \mathrm{hrs}$ post-OGTT, which were lower in individuals with AITD.

Nevertheless, since both clinical and subclinical thyroid disorders have been associated with insulin resistance, in the present study we included patients with normal thyroid function ${ }^{30.32}$ either with or without L-thyroxine replacement treatment to eliminate this confounding factor.

In previous studies, the correlation between DM and thyroid dysfunction has been extensively studied, mostly in regard to DM1, where a causative pathogenic mechanism has been speculated; common 
Table 1. Demographic and biochemical characteristics of the study groups.

\begin{tabular}{|c|c|c|c|c|}
\hline & Pre-diabetes $(n=166)$ & $\operatorname{AITD}(n=53)$ & Non-AITD $(n=113)$ & p-value \\
\hline Age (years) & $50(20,18-79)$ & $49.5(20,18-77)$ & $53(18,31-79)$ & 0.43 \\
\hline Females (\%) & $132(79.5 \%)$ & $44(83 \%)$ & $88(77.9 \%)$ & 0.44 \\
\hline $\mathrm{BMI}\left(\mathrm{kg} / \mathrm{m}^{2}\right)$ & $32.1(10,18-59)$ & $31.4(12,18-59)$ & $32.4(7,22-58)$ & 0.25 \\
\hline Waist $(\mathrm{cm})$ & $97.5 \pm 16.4$ & $98.6 \pm 14.8$ & $96.9 \pm 17.4$ & 0.58 \\
\hline Waist-to-height ratio & $0.58(0.13,0-0.88)$ & $0.58(0.15,0-0.88)$ & $0.59(0.11,0.0 .81)$ & 0.51 \\
\hline $\mathrm{TSH}(\mu \mathrm{IU} / \mathrm{mL}, \mathrm{mIU} / \mathrm{L})$ & $2.3 \pm 1.1$ & $2.3 \pm 1.0$ & $2.3 \pm 1.1$ & 0.065 \\
\hline Thyroxin replacement (\%) & $70(42.2)$ & $31(58.5)$ & $39(34.5)$ & $0.004^{*}$ \\
\hline Dyslipidemia & $68(56.2)$ & $22(51.2)$ & $46(59)$ & 0.41 \\
\hline $\begin{array}{l}\text { Total Cholesterol (mg/dL, } \\
\mathrm{mmol} / \mathrm{L})\end{array}$ & $204.4 \pm 38(5.3 \pm 1.0)$ & $208 \pm 43.5(5.4 \pm 1.1)$ & $202.4 \pm 34.7(5.2 \pm 0.9)$ & 0.48 \\
\hline $\mathrm{HDL}(\mathrm{mg} / \mathrm{dL})$ & $55.2 \pm 15.3(1.4 \pm 0.4)$ & $56.1 \pm 16.4(1.5 \pm 0.4)$ & $54.7 \pm 14.8(1.4 \pm 0.4)$ & 0.65 \\
\hline $\mathrm{LDL}(\mathrm{mg} / \mathrm{dl})$ & $127.3 \pm 33.1(3.3 \pm 0.9)$ & $131.9 \pm 38(3.4 \pm 1.0)$ & $124.7 \pm 30(3.2 \pm 0.8)$ & 0.31 \\
\hline Triglycerides (mg/dL) & $\begin{array}{c}109.5(60,41-409) \\
{[1.24(0.68,0.46-4.62)]}\end{array}$ & $\begin{array}{c}110(51,41-320)[1.24 \\
(0.58,0.46-3.61)]\end{array}$ & $\begin{array}{c}109(75,45-409) \\
{[1.23(0.85,0.51-4.62)]}\end{array}$ & \\
\hline Hypertension & $53(44.2)$ & $3(7.1)$ & $13(16.7)$ & 0.17 \\
\hline $\mathrm{SBP}(\mathrm{mmHg})$ & $134(21,108-166)$ & $135(21,108-166)$ & $131(25,112-166)$ & \\
\hline $\mathrm{DBP}(\mathrm{mmHg})$ & $88.2 \pm 11.6$ & $86.1 \pm 11.2$ & $89.4 \pm 11.8$ & 0.18 \\
\hline HR (bpm) & $76(21,43-128)$ & $78(20,43-128)$ & $76(19,59-112)$ & \\
\hline Family History of Diabetes & $56(46.7)$ & $19(44.2)$ & $37(48.1)$ & 0.68 \\
\hline $\mathrm{TgAb}$ and /or TPOAb (\%) & $53(31.9)$ & $53(100 \%)$ & 0 & $\mathrm{~N} / \mathrm{A}$ \\
\hline Glucose $0 \mathrm{~min}(\mathrm{mg} / \mathrm{dL}, \mathrm{nmol} / \mathrm{L})$ & $\begin{array}{c}104(9,74-125) \\
{[5.77(0.5,4.11-6.94)]}\end{array}$ & $\begin{array}{c}104(9,86-124) \\
{[5.77(0.5,4.77-6.88)]}\end{array}$ & $\begin{array}{c}104(10,74-154) \\
{[5.77(0.56,4.11-8.55)]}\end{array}$ & 0.36 \\
\hline Glucose $60 \mathrm{~min}(\mathrm{mg} / \mathrm{dL}, \mathrm{nmol} / \mathrm{L})$ & $\begin{array}{c}163(60,65-275) \\
{[9.05(3.33,3.61-15.26)]}\end{array}$ & $\begin{array}{c}157(54,65-237) \\
{[8.71(3,3.61-13.15)]}\end{array}$ & $\begin{array}{c}169(63,78-275) \\
{[9.38(3.5,4.33-15.26)]}\end{array}$ & 0.06 \\
\hline $\begin{array}{l}\text { Glucose } 120 \mathrm{~min}(\mathrm{mg} / \mathrm{dL}, \\
\mathrm{nmol} / \mathrm{L})\end{array}$ & $\begin{array}{c}108.5(46,40-199) \\
{[6.02(2.55,2.22-11.04)]}\end{array}$ & $\begin{array}{c}100(40,56-199) \\
{[5.55(2.22,3.11-11.04)]}\end{array}$ & $\begin{array}{c}112(59,40-199) \\
{[6.22(3.27,2.22-199)]}\end{array}$ & 0.07 \\
\hline Insulin $0 \min (\mu \mathrm{IU} / \mathrm{mL}, \mathrm{pmol} / \mathrm{L})$ & $\begin{array}{c}12.5(9,3-34)[86.81(62.5 \\
20.83-236.11)]\end{array}$ & $\begin{array}{c}12.1(9,3-34)[84.03(62.5, \\
20.83-236.11)]\end{array}$ & $\begin{array}{c}13(8,3-28)[90.28 \\
(55.6,20.83-194.44)]\end{array}$ & 0.42 \\
\hline $\begin{array}{l}\text { Insulin } 60 \mathrm{~min}(\mu \mathrm{IU} / \mathrm{mL} \text {, } \\
\mathrm{pmol} / \mathrm{L})\end{array}$ & $\begin{array}{l}92.2(82,15-688) \\
{[640.28(569.44,} \\
104.17-4777.78)]\end{array}$ & $\begin{array}{c}103.8(124,23-598)[720.83 \\
(861.11,159.72-4152.78)\end{array}$ & $\begin{array}{l}81.5(82,15-688) \\
{[565.97(569.44} \\
104.17-4777.78)]\end{array}$ & 0.059 \\
\hline $\begin{array}{l}\text { Insulin } 120 \mathrm{~min}(\mu \mathrm{IU} / \mathrm{mL} \text {, } \\
\mathrm{pmol} / \mathrm{L})\end{array}$ & $\begin{array}{c}3.3(68,4-405) \\
{[370.14(472.22,} \\
27.8-2812.5)] \\
\end{array}$ & $\begin{array}{l}55.8(82,10-405)[387.5 \\
(566.44,69.44-2812.5)]\end{array}$ & $\begin{array}{l}51.8(64,4-284) \\
{[359.72(444.44,} \\
27.78-1972.22)] \\
\end{array}$ & 0.068 \\
\hline hsCRP (mg/L, nmol/L) & $\begin{array}{c}1.7(4,0-16) \\
{[16.2(38.1,0-152.4)]}\end{array}$ & $\begin{array}{c}2.8(5,0-16) \\
{[26.7(47.6,0-152.4)]}\end{array}$ & $\begin{array}{c}1.2(3,0-13) \\
{[11.4(28.6,0-123.8)]}\end{array}$ & $0.008^{*}$ \\
\hline HbA1c (\%) & $5.7(0.5,4.2-6.5)$ & $5.7(0.7,4.2-6.5)$ & $5.7(0,5-6)$ & 0.58 \\
\hline IFG $(\%)$ & $153(92.2)$ & $50(94.3)$ & $103(91.2)$ & 0.55 \\
\hline IGT $(\%)$ & $37(22.3)$ & $5(9.4)$ & $32(28.3)$ & $0.004^{*}$ \\
\hline $\begin{array}{l}\text { Insulin resistance } \\
\text { (HOMA-IR/QUICKI) }\end{array}$ & $121(72.9 \%)$ & $41(77.4 \%)$ & $80(70.8 \%)$ & 0.37 \\
\hline \multicolumn{5}{|c|}{ Statical Insulin Resistance Indices (statical IRI) } \\
\hline Glucose/insulin (GIR) & $8.5(6,3-41)$ & $9.2(7,3-41)$ & $7.9(5,4-32)$ & 0.37 \\
\hline QUICKI & $0.32(0.04,0.28-0.42)$ & $0.32(0.04,0.28-0.42)$ & $0.32(0.03,0.29-0.40)$ & 0.49 \\
\hline HOMA-IR & $3.3(2.5,0.6-9.5)$ & $3.1(2.6,0.6-9.5)$ & $3.5(2.2,0.8-7.7)$ & 0.49 \\
\hline $1 /$ fasting insulin & $0.08(0.07,0.03-0.4)$ & $0.08(0.07,0.03-0.4)$ & $0.08(0.05,0.04-0.3)$ & 0.42 \\
\hline \multicolumn{5}{|c|}{ Dynamic Insulin Resistance Index (dynamic IRI) } \\
\hline MATSUDA index & $3.03(2.68,0.72-13)$ & $3.03(3.03,0.83-13)$ & $2.8(2.3,0.72-10.83)$ & 0.31 \\
\hline \multicolumn{5}{|c|}{ Statical $\beta$-cell secretion index (statical ISI) } \\
\hline HOMA-B & $38.9(27.3,5.3-124.5)$ & $35.8(28.6,5.3-124.5)$ & $42.1(23.3,7.8-87.7)$ & 0.37 \\
\hline \multicolumn{5}{|c|}{ Dynamic $\beta$-cell secretion indices (dynamic ISI) } \\
\hline $1^{\text {st }}$ phase insulin release & $917.6(909.6,-282.5-2772.5)$ & $864.3(826.9,-282.5-2772.5)$ & $\begin{array}{c}1029.3(837.1 \\
323-2614.2)\end{array}$ & 0.033 \\
\hline $2^{\text {nd }}$ phase insulin release & $316.5(275.6,24.7-906.3)$ & $286.5(254.7,24.7-906.3)$ & $\begin{array}{l}354.8(268.4 \\
132.8-851.1) \\
\end{array}$ & 0.035 \\
\hline AUC insulin/glucose & $0.49(0.45,0.09-2.42)$ & $0.45(0.41,0.09-2.06)$ & $0.54(0.49,0.20-2.42)$ & 0.029 \\
\hline \multicolumn{5}{|c|}{ Combined Insulin Resistance and $\beta$-cell secretion index } \\
\hline Disposition index & $0.08(0.07,-0.01-0.55)$ & $0.07(0.06,-0.01-0.51)$ & $0.09(0.09,0.006-0.55)$ & 0.02 \\
\hline
\end{tabular}


susceptibility genes were identified in both autoimmune diseases ${ }^{16}$. An apparent correlation between AITD and DM2 has been speculated in some, but not all the studies, although no pathogenic mechanism has been identified ${ }^{13,14,33-37}$. In a recent study, one in five DM2 subjects had AITD, as opposed to one in twenty seen in control subjects ${ }^{14}$. Although there are studies in agreement with this finding ${ }^{13,38,39}$, other studies did not document any association between AITD and DM2, as in the present study ${ }^{13,33,36,37}$. In addition, the presence of metabolic syndrome, with or without obesity, has been shown to be related to AITD in some, but not all studies ${ }^{40-42}$, while similarly discordant results were published regarding the association of dyslipidemia with AITD ${ }^{15,40,41,43,44}$. In favor of an association between AITD and cardiovascular risk factors is the fact that AITD has been related to indirect indices of atherosclerosis, such as carotid intima-media thickness ${ }^{44}$.

Several reasons have been put forward to account for the above-mentioned contradictory findings, such as differences in the assays used to determine thyroid auto-antibodies (more sensitive methodologies may result in a higher association), along with inherent variability of the diabetic populations studied, such as duration of diabetes, diabetic control, and medications used ${ }^{14}$. In order to eliminate the impact of the above differences on indices of insulin secretion and/ or action (IRI or ISI) and to clarify the relationship of AITD with carbohydrate metabolism abnormalities, we have recruited euthyroid patients with prediabetes not receiving any antidiabetic or insulin-sensitizing medication.

Our data showed that $30 \%$ of euthyroid patients with prediabetes have AITD, a percentage that is similar to the $32.9 \%$ percentage found in a cohort of non-pregnant patients with DM2 with unknown thyroid function ${ }^{45}$. As a high proportion of patients with prediabetes are likely to develop frank DM, we have speculated that the presence of AITD may confer to prediabetics a higher risk of progression to DM. However, despite the fact that the AITD group exhibited a higher (low-grade) inflammatory state, no difference in insulin resistance between the two groups was observed, while, even further, thyroid autoimmunity was associated with a better $\beta$-cell secretory profile, which was reflected in the higher DI, the lower glycemic excursions at $1 \mathrm{hr}$ and $2 \mathrm{hrs}$ post-OGTT and, consequently, in the lower prevalence of IGT in the AITD group. In other words, dysglycemia in individuals with AITD was mainly associated with impaired fasting rather than impaired tolerance of glucose. Clinical studies suggest that the site of insulin resistance varies between IFG and IGT, the first being related mainly with severe hepatic insulin resistance with normal or near-normal muscle insulin resistance, while the latter with only mild hepatic insulin resistance, but with severe insulin resistance at the periphery ${ }^{46}$. AITD may have some impact and inflammatory factors ${ }^{47}$, such as the levels of serum interleukin (IL)- 6 , tumor necrosis factor- $\alpha$ (TNF- $\alpha$ ), IL-12, IL-10, and HOMA-IR, were higher in patients with AITD and hypothyroidism compared to ones with AITD and normal levels of thyroid hormones ${ }^{48}$. On the other hand, we have shown similar TSH levels between groups, suggesting that TSH did not influence our results. Thyroid replacement treatment per se may also influence our findings ${ }^{49}$, since more patients on AITD group were on treatment; however, the subgroups of AITD, with and without replacement treatment, did not differ in any of the parameters studied. Another factor that may be involved is the change in metabolomic patterns and fatty acid metabolism, that may promote insulin resistance. However, the isolated TSH increase, as it was often observed in obesity or euthyroid patients with AITD, is not correlated with insulin metabolism. Slight changes in thyroid hormones may centrally interact with AMP-activated protein kinase (AMPK), decreasing peripheral glucose production and linking glucose regulation to fatty acids synthesis via the carboxylation of acetyl-CoA to form malonyl-CoA, which is catalyzed by acetyl-CoA carboxylase ${ }^{50}$.

Therefore, it may be speculated that the increased low-grade inflammation of the AITD group is preferentially inducing insulin resistance at the hepatic level, rather than the muscle or the adipose tissue level. It cannot be excluded, of course, that our findings may be the result of plain chance. The small sample size, the lack of more specific inflammatory markers ${ }^{49,51}$, as well as the fact that insulin resistance was not assessed by more sophisticated techniques, do not allow for more robust conclusions to be drawn ${ }^{52}$.

Our study has some limitations that need to be considered. Patients with AITD were studied cross-sectionally, being at various periods of disease evolution and AITD effect on thyroid function. We also recruited patients from the endocrine and diabetic outpatient clinics, who present a source of bias. This explains the higher number of females participating in the study, which could be a potential bias for the assessment of autoimmunity of the population participating in the study. However, despite the small numbers of patients studied in subpopulations analysis, the fact that similar results were seen in normal-weight and lean patients implies that this relationship is real and independent from obesity. Moreover, we found out one patient confirming the previously documented $4 \%$ presence of anti-GAD ${ }^{38}$ that inclusion or exclusion did not affect the results. 


\section{Conclusions}

In conclusion, prediabetic patients with AITD exhibit a better $\beta$-cell dependent secretory profile, as assessed by mathematical models associated in spite of an increased inflammatory state. Future larger studies using a prospective design may shed light in the exact mechanism that explains the major impact that thyroid autoimmunity has on insulin-resistance instead of $\beta$-cell secretion.

\section{Author Contributions:}

K.I.A., G.B. equally contributed to the design of the study, to patients recruitment, analysis of the findings and writing of the manuscript; I.A., L.I.B., P.M., A.K., V.M. contributed to the collection of the data; T.G.P. contributed to data analysis and revision of the manuscript; K.M., L.D. contributed to the design of the study and revision of the manuscript; G.A.K., S.L. equally contributed to the design of the study, to patients recruitment, and revision of the manuscript. All authors read and approved the final manuscript.

\section{Compliance with Ethics Requirements:}

„The authors declare no conflict of interest regarding this article"

„The authors declare that all the procedures and experiments of this study respect the ethical standards in the Helsinki Declaration of 1975, as revised in 2008(5), as well as the national law"

"No funding for this study"

\section{Acknowledgments:}

None.

\section{References}

1. Tamayo T, Rosenbauer J, Wild SH, et al. Diabetes in Europe: an update. Diabetes Research and Clinical Practice. 2014;103: 206-217.

2. Bjoro T, Holmen J, Krüger O, et al. Prevalence of thyroid disease, thyroid dysfunction and thyroid peroxidase antibodies in a large, unselected population. The Health Study of Nord-Trondelag (HUNT). European Journal of Endocrinology. 2000;143: 639-647.

3. Hollowell JG, Staehling NW, Flanders WD, et al. Serum TSH, T(4), and thyroid antibodies in the United States population (1988 to 1994): National Health and Nutrition Examination Survey (NHANES III). The Journal of Clinical Endocrinology and Metabolism. 2002;87: 489-499.

4. Soriguer F, Goday A, Bosch-Comas A, et al. Prevalence of diabetes mellitus and impaired glucose regulation in Spain: the Di@bet.es Study. Diabetologia. 2012;55: 88-93.

5. Feely J, Isles TE. Screening for thyroid dysfunction in diabetics. British Medical Journal. 1979;1: 1678.
6. Gray RS, Irvine WJ, Clarke BF. Screening for thyroid dysfunction in diabetics. British Medical Journal. 1979;2: 1439.

7. Perros P, McCrimmon RJ, Shaw G, Frier BM. Frequency of thyroid dysfunction in diabetic patients: value of annual screening. Diabetic Medicine. 1995;12: 622-627.

8. Papazafiropoulou A, Sotiropoulos A, Kokolaki A, Kardara M, Stamataki P, Pappas S. Prevalence of thyroid dysfunction among greek type 2 diabetic patients attending an outpatient clinic. Journal of Clinical Medicine Research. 2010;2: 75-78.

9. Palma CC, Pavesi M, Nogueira VG, et al. Prevalence of thyroid dysfunction in patients with diabetes mellitus. Diabetology and Metabolic Syndrome. 2013;5: 58.

10. Gierach M, Gierach J, Skowrońska A, et al. Hashimoto's thyroiditis and carbohydrate metabolism disorders in patients hospitalised in the Department of Endocrinology and Diabetology of Ludwik Rydygier Collegium Medicum in Bydgoszcz between 2001 and 2010. Endokrynologia Polska. 2012;63: 14-17.

11. Kordonouri O, Charpentier N, Hartmann R. GADA positivity at onset of type 1 diabetes is a risk factor for the development of autoimmune thyroiditis. Pediatric Diabetes. 2011;12: 31-33

12. Radetti G, Paganini C, Gentili L, et al. Frequency of Hashimoto's thyroiditis in children with type 1 diabetes mellitus. Acta Diabetologica. 1995;32: 121-124

13. Cardoso C, Ohwovoriole AE, KuKu SF. A study of thyroid function and prevalence of thyroid autoantibodies in an African diabetic population. Journal of Diabetes and its Complications. 1995;9: 37-41.

14. Sarfo-Kantanka O, Sarfo FS, Ansah EO, et al. Frequency and determinants of thyroid autoimmunity in Ghanaian type 2 diabetes patients: a case-control study. BMC Endocrine Disorders. 2017;17: 2

15. Chen Y, Zhu C, Chen Y, Wang N, Li Q, Han B, Zhao L, Chen C, Zhai H, Zhang L, Lu Y. Are Thyroid Autoimmune Diseases Associated with Cardiometabolic Risks in a Population with Normal Thyroid-Stimulating Hormone? Mediators of Inflammation. 2018;2018: 1856137.

16. Hage M, Zantout MS, Azar ST. Thyroid disorders and diabetes mellitus. Journal of Thyroid Research. 2011;2011: 439463

17. American Diabetes Association. Classification and diagnosis of diabetes. Diabetes Care. 2017;40 Suppl 1:S11-S24.

18. Diamanti-Kandarakis E, Piperi C, Alexandraki KI, et al. The acute effect of orlistat on dietary glycotoxins in diabetics and healthy women. Minerva Endocrinologica. 2009;34: 97-104.

19. Chopra HK, Ram CVS. Recent guidelines for hypertension. Circulation Research. 2019;124: 984-986.

20. Williams B, Mancia G, Spiering W, et al. 2018 ESC/ESH Guidelines for the management of arterial hypertension. European Heart Journal. 2018;39: 3021-3104.

21. Whelton PK, Carey RM, Aronow WS, et al. 2017 ACC/ AHA/AAPA/ABC/ACPM/AGS/APhA/ASH/ASPC/ NMA/PCNA Guideline for the Prevention, Detection, Evaluation, and Management of High Blood Pressure in Adults: Executive Summary: A Report of the American College of Cardiology/American Heart Association Task Force on Clinical Practice Guidelines. Journal of the American College of Cardiology. 2018;71: 2199-2269.

22. Jellinger PS, Handelsman Y, Rosenblit PD, et al. American Association of Clinical Endocrinologists and American College of Endocrinology Guidelines for management of dyslipidemia and prevention of cardiovascular disease. Endocrine Practice. 2017;23 Suppl 2: 1-87. 
23. Stumvoll M, Mitrakou A, Pimenta W, et al. Use of the oral glucose tolerance test to assess insulin release and insulin sensitivity. Diabetes Care. 2000;23: 295-301.

24. Katz A, Nambi SS, Mather K, et al. Quantitative insulin sensitivity check index: a simple, accurate method for assessing insulin sensitivity in humans. The Journal of Clinical Endocrinology and Metabolism. 2000;85: 2402-2410.

25. Wallace TM, Levy JC, Matthews DR. Use and abuse of HOMA modeling. Diabetes Care. 2004;27: 1487-1495.

26. Matsuda M, DeFronzo RA. Insulin sensitivity indices obtained from oral glucose tolerance testing: comparison with the euglycemic insulin clamp. Diabetes Care. 1999;22: 1462-1470.

27. Mastorakos G, Koliopoulos C, Deligeoroglou E, Diamanti-Kandarakis E, Creatsas G. Effects of two forms of combined oral contraceptives on carbohydrate metabolism in adolescents with polycystic ovary syndrome. Fertility and Sterility. 2006;85: 420-427.

28. Utzschneider KM, Prigeon RL, Faulenbach MV, et al. Oral disposition index predicts the development of future diabetes above and beyond fasting and 2-h glucose levels. Diabetes Care. 2009;32: 335-341.

29. Belli SH, Graffigna MN, Oneto A, Otero P, Schurman L, Levalle OA. Effect of rosiglitazone on insulin resistance, growth factors, and reproductive disturbances in women with polycystic ovary syndrome. Fertility and Sterility. 2004;81: 624-629

30. Dimitriadis G, Mitrou P, Lambadiari V, et al. Insulin action in adipose tissue and muscle in hypothyroidism. The Journal of Clinical Endocrinology and Metabolism. 2006;91: 4930-4937.

31. Maratou E, Hadjidakis DJ, Kollias A, et al. Studies of insulin resistance in patients with clinical and subclinical hypothyroidism. European Journal of Endocrinology. 2009;160: 785-790.

32. Dimitriadis G, Baker B, Marsh H, et al. Effect of thyroid hormone excess on action, secretion, and metabolism of insulin in humans. American Journal of Physiology. 1985;248: E593-601.

33. Afkhami-Ardekani M, Rashidi M, Shojaoddiny-Ardekani A. Evaluation of thyroid autoantibodies in type 2 diabetes. Iranian Journal of Diabetes and Obesity. 2009;1: 1-4.

34. Akbar DH, Ahmed MM, Al-Mughales J. Thyroid dysfunction and thyroid autoimmunity in Saudi type 2 diabetics. Acta Diabetologica. 2006;43: 14-18.

35. Yasmin T, Ghafoor F, Malik T, S RN, Khan AU. Pattern of thyroid autoimmunity in type 1 and type 2 diabetics. Journal of the College of Physicians and Surgeons Pakistan. 2006;16: 751-754.

36. Radaideh AR, Nusier MK, Amari FL, et al. Thyroid dysfunction in patients with type 2 diabetes mellitus in Jordan. Saudi Medical Journal. 2004;25: 1046-1050.

37. Ortega-González C1, Liao-Lo A, Ramírez-Peredo J, Cariño N, Lira J, Parra A. Thyroid peroxidase antibodies in Mexican-born healthy pregnant women, in women with type 2 or gestational diabetes mellitus, and in their offspring. Endocrine Practice. 2000;6: 244-248.

38. Akbar DH, Ahmed MM, Al-Mughales J. Thyroid dysfunction and thyroid autoimmunity in Saudi type 2 diabetics. Acta Diabetologica. 2006;43: 14-18.
39. Yasmin T, Ghafoor F, Malik T, S RN, Khan AU. Pattern of thyroid autoimmunity in type 1 and type 2 diabetics. Journal of the College of Physicians and Surgeons Pakistan. 2006;16: 751-754.

40. Wells BJ, Hueston WJ. Are thyroid peroxidase antibodies associated with cardiovascular disease risk in patients with subclinical hypothyroidism? Clinical Endocrinology (Oxford). 2005;62: 580-584.

41. Siemińska L, Wojciechowska C, Walczak K, et al. Associations between metabolic syndrome, serum thyrotropin, and thyroid antibodies status in postmenopausal women, and the role of interleukin 6. Endokrynologia Polska. 2015;66: 394-403

42. Agbaht K, Mercan Y, Kutlu S, Alpdemir MF, Sezgin T. Obesity with and without metabolic syndrome: do vitamin $\mathrm{D}$ and thyroid autoimmunity have a role? Diabetes Research and Clinical Practice. 2014;106: 27-34.

43. Kang D, Yin Q, Yan X, et al. Serum cholesterol levels in middle-aged euthyroid subjects with positive thyroid peroxidase antibodies. International Journal of Clinical and Experimental Medicine. 2015;8: 21623-21628.

44. Topaloglu O, Gokay F, Kucukler K, et al. Is autoimmune thyroiditis a risk factor for early atherosclerosis in premenopausal women even if in euthyroid status? Endocrine. 2013;44: 145-151.

45. Kamrul-Hasan AB, Akter F, Selim S, et al. Thyroid function and autoantibody status in Bangladeshi patients with type 2 diabetes mellitus. Thyroid Research and Practice. 2018;15: 132-137.

46. Abdul-Ghani MA, Tripathy D, DeFronzo RA. Contributions of beta-cell dysfunction and insulin resistance to the pathogenesis of impaired glucose tolerance and impaired fasting glucose. Diabetes Care. 2006;29: 1130-1139.

47. Alexandraki K, Piperi C, Kalofoutis C, Singh J, Alaveras A, Kalofoutis A. Inflammatory process in type 2 diabetes: The role of cytokines. Annals of the New York Academy of Sciences. 2006;1084: 89-117.

48. Lei Y, Yang J, Li H, Zhong H, Wan Q. Changes in glucose-lipid metabolism, insulin resistance, and inflammatory factors in patients with autoimmune thyroid disease. Journal of Clinical Laboratory Analysis 2019;33: e22929.

49. Liu J, Chen Z, Liu M, Jia Y, Yao Z, Wang G. Levothyroxine replacement alleviates thyroid destruction in hypothyroid patients with autoimmune thyroiditis: evidence from a thyroid MRI study. Frontiers in Endocrinology (Lausanne). 2019;10: 138.

50. Duntas LH, Orgiazzi J, Brabant G. The interface between thyroid and diabetes mellitus. Clinical Endocrinology. 2011;75: $1-9$.

51. Alexandraki KI, Piperi C, Ziakas PD, et al. Cytokine secretion in long-standing diabetes mellitus type 1 and 2: associations with low-grade systemic inflammation. Journal of Clinical Immunology. 2008;28: 314-321.

52. Diamanti-Kandarakis E, Kouli C, Alexandraki K, Spina G. Failure of mathematical indices to accurately assess insulin resistance in lean, overweight, or obese women with polycystic ovary syndrome. The Journal of Clinical Endocrinology and Metabolism. 2004;89: 1273-1276. 